\title{
Analog Modulation of Mossy Fiber Transmission Is Uncoupled from Changes in Presynaptic $\mathrm{Ca}^{2+}$
}

\author{
Ricardo Scott, Arnaud Ruiz, Christian Henneberger, Dimitri M. Kullmann, and Dmitri A. Rusakov \\ Institute of Neurology, University College London, London WC1N 3BG, United Kingdom
}

Subthreshold somatic depolarization has been shown recently to modulate presynaptic neurotransmitter release in cortical neurons. To understand the mechanisms underlying this mode of signaling in the axons of dentate granule cells (hippocampal mossy fibers), we have combined two-photon $\mathrm{Ca}^{2+}$ imaging with dual-patch recordings from somata and giant boutons forming synapses on CA3 pyramidal cells. In intact axons, subthreshold depolarization propagates both orthodromically and antidromically, with an estimated length constant of 200-600 $\mu \mathrm{m}$ depending on the signal waveform. Surprisingly, presynaptic depolarization sufficient to enhance glutamate release at mossy fiber-CA3 pyramidal cell synapses has no detectable effect on either basal $\mathrm{Ca}^{2+}$-dependent fluorescence or actionpotential-evoked fluorescence transients in giant boutons. We further estimate that neurotransmitter release varies with presynaptic $\mathrm{Ca}^{2+}$ entry with a 2.5-power relationship and that depolarization-induced synaptic facilitation remains intact in the presence of highaffinity presynaptic $\mathrm{Ca}^{2+}$ buffers or after blockade of local $\mathrm{Ca}^{2+}$ stores. We conclude that depolarization-dependent modulation of transmission at these boutons does not rely on changes in presynaptic $\mathrm{Ca}^{2+}$.

Key words: synaptic transmission; mossy fiber; analog modulation; hippocampus; dual-patch recordings; biophysical modeling

\section{Introduction}

Transient subthreshold depolarization of dentate granule cells enhances transmitter release at remote synapses formed by axons [mossy fibers (MFs)] on CA3 pyramidal cells in the hippocampus (Alle and Geiger, 2006). Surprisingly, the estimated $40-45 \%$ enhancement of transmission is not accompanied by a detectable change in presynaptic $\mathrm{Ca}^{2+}$ currents recorded from giant $\mathrm{MF}$ boutons in whole-terminal mode (Alle and Geiger, 2006). In contrast, electrotonic facilitation of transmission between cortical pyramidal cells does involve an enhanced presynaptic $\mathrm{Ca}^{2+}$ signal (Shu et al., 2006). A possible explanation for the paradoxical absence of change in evoked $\mathrm{Ca}^{2+}$ currents at giant MF boutons is that the enhancement in neurotransmitter release relies on changes in resting $\mathrm{Ca}^{2+}$ and/or $\mathrm{Ca}^{2+}$ release from internal stores (Lauri et al., 2003; Scott and Rusakov, 2006). However, chelation of presynaptic $\mathrm{Ca}^{2+}$ using a high concentration of EGTA (10 $\mathrm{mM}$ ) only led to a nonsignificant attenuation of this enhancement (Alle and Geiger, 2006), casting doubt on the role of intraterminal $\mathrm{Ca}^{2+}$ sources in electrotonic facilitation of neurotransmitter release.

To address the mechanisms of analog modulation of neuro-

Received Nov. 21, 2007; revised May 14, 2008; accepted June 11, 2008.

This work was supported by the Wellcome Trust, the Medical Research Council UK, the Human Frontier Science Program, and the European Union (Promemoria). We thank P. Ragunathan for help with some experiments, and K. Volynski and M. Walker for valuable comments.

Correspondence should be addressed to either Dmitri A. Rusakov or Ricardo Scott, Institute of Neurology, University College London, Queen Square, London WC1N 3BG, UK. E-mail: d.rusakov@ion.ucl.ac.uk or r.scott@ion.ucl.ac.uk.

A. Ruiz's present address: Department of Pharmacology, The School of Pharmacy, University of London, London WC1N 1AX, UK.

DOI:10.1523/JNEUROSCI.1296-08.2008

Copyright $\odot 2008$ Society for Neuroscience $\quad$ 0270-6474/08/287765-09\$15.00/0 transmitter release from MF boutons more directly, here we assess the effects of presynaptic depolarization on $\mathrm{Ca}^{2+}$ kinetics in MF boutons using two-photon excitation microscopy. We have previously shown that long-term (minutes) changes in granule cell membrane potential affect both resting $\mathrm{Ca}^{2+}$ and actionpotential-evoked $\mathrm{Ca}^{2+}$ entry in MFs within 100-200 $\mu \mathrm{m}$ of the soma (Ruiz et al., 2003) but not as far as area CA3 (Scott and Rusakov, 2006). However, long-term depolarization potentially alters the state of voltage-gated ion channels $\left(\mathrm{Na}^{+}, \mathrm{K}^{+}, \mathrm{Ca}^{2+}\right)$ that shape action-potential-evoked presynaptic $\mathrm{Ca}^{2+}$ currents. These effects might differ from the consequences of short-term depolarization such as studied by Alle and Geiger (2006). To address whether depolarization-mediated facilitation in CA3 involves changes in resting $\mathrm{Ca}^{2+}$ and/or $\mathrm{Ca}^{2+}$ store signaling, we combine $\mathrm{Ca}^{2+}$ imaging with dual-patch recordings from somata and axons of granule cells. We confirm directly that depolarization propagates electrotonically along the entire length of intact axons between the granule cells and giant boutons in CA3. Surprisingly, however, subthreshold depolarization, either local or remote, has no detectable effect on presynaptic $\mathrm{Ca}^{2+}$ signaling (either entering through channels or released from internal sources) in these boutons. Furthermore, depolarization (or high external $\mathrm{K}^{+}$)-induced enhancement of release at these synapses is not affected by buffering presynaptic $\mathrm{Ca}^{2+}$ or by blocking $\mathrm{Ca}^{2+}$ stores, although neurotransmitter release varies with action potential-dependent $\mathrm{Ca}^{2+}$ entry with a power relationship of $\sim 2.5$. The results argue that a $\mathrm{Ca}^{2+}$-independent but voltagedependent mechanism underlies analog control of transmission at MF synapses. 


\section{Materials and Methods}

Electrophysiology. Acute $300 \mu \mathrm{m}$ hippocampal slices from three- to four-week-old male Sprague Dawley rats were transferred to a submersion-type recording chamber (Scientific Systems Design) and superfused with (in $\mathrm{mm}$ ) $124 \mathrm{NaCl}, 2.5 \mathrm{KCl}, 2 \mathrm{CaCl}_{2}, 1 \mathrm{MgCl}_{2}, 26$ $\mathrm{NaHCO}_{3}$, and 10 glucose, and bubbled with $95 \% \mathrm{O}_{2} / 5 \% \mathrm{CO}_{2}$. The slice orientation that allows intact MFs to be preserved was detailed previously (Scott and Rusakov, 2006). The internal solution included (in $\mathrm{mm}$ ) $135 \mathrm{~K}$ methanesulfonate, $2 \mathrm{MgCl}_{2} 10$ HEPES, $10 \mathrm{Na}$ phosphocreatine, 4 NaATP, $0.4 \mathrm{NaGTP}$, and fluorophores as indicated. Unless specified otherwise, dentate granule cells were held at -80 $\mathrm{mV}$; cells were discarded if their resting potential, in current-clamp mode, increased above $-70 \mathrm{mV}$ during the experiment. Single orthodromic escape action currents were evoked by a $2 \mathrm{~ms}$ command voltage pulse. Recording sweeps (normally $500 \mathrm{~ms}$ long) were collected at $5 \mathrm{kHz}$ with $30 \mathrm{~s}$ or $1 \mathrm{~min}$ intervals. Experiments were carried at $22-24^{\circ} \mathrm{C}$ unless specified otherwise; $1 \mu \mathrm{M}$ tetrodotoxin (TTX) was added where shown. Receptor antagonists were purchased from Tocris Bioscience, and fluorescent probes were purchased from Invitrogen. All animal handling procedures followed current UK regulations.

To record from an individual MF bouton, we approached it (imaged in the Alexa emission channel 50-100 $\mu \mathrm{m}$ deep in the slice) with a patch pipette, in voltage-clamp configuration, and applied negative pressure to achieve loose patch (100-200 M $\Omega$ seal resistance). Next, we determined the minimal external command voltage that would induce an action potential in the axon (which invariably evoked a presynaptic $\mathrm{Ca}^{2+}$ transient and an antidromic action current detected at the soma): this voltage was considered to reflect local depolarization up to the spiking threshold, which is $\sim 25 \mathrm{mV}$ above the resting membrane potential in these boutons (Geiger and Jonas, 2000).

Two-photon excitation fluorescence imaging. We used a Radiance 2000 or Radiance 2100 imaging system (Zeiss/Bio-Rad) optically linked to a MaiTai femtosecond pulsed infrared laser (SpectraPhysics/Newport) and integrated with patch-clamp electrophysiology (Rusakov and Fine, 2003; Scott and Rusakov, 2006). Granule cells held in whole-cell mode were loaded with two fluorophores: a morphological tracer Alexa Fluor $594(20-40 \mu \mathrm{M})$ and either of two high-affinity $\mathrm{Ca}^{2+}$ indicators, Fluo-4 $(200 \mu \mathrm{M})$ or Oregon Green BAPTA-1 (OGB-1; $200 \mu \mathrm{M})$, as indicated. Fluorophores were excited in two-photon mode at $800 \mathrm{~nm}$. The technique to trace and to identify giant boutons synapsing in the CA3 region $500-1000 \mu \mathrm{m}$ from the soma is described by Scott and Rusakov (2006). Depending on the task, we focused on presynaptic boutons identified by their distinct morphology and location (Acsády et al., 1998; Scott and Rusakov, 2006), at the maximal optical resolution $(\sim 0.2 \mu \mathrm{m}, 70 \mathrm{~nm}$ per pixel). The success rate for imaging a giant MF bouton in CA3 supplied by a given granule cell was $<10 \%$. Recordings started at least $30 \mathrm{~min}$ after obtaining a whole-cell configuration (Scott and Rusakov, 2006).

Fluorescence line scans were recorded at $500 \mathrm{~Hz}(500$ or $1000 \mathrm{~ms}$ sweeps, intersweep interval, $30 \mathrm{~s}$ or $1 \mathrm{~min}$ ) and analyzed off-line. To probe the effects of somatic depolarization, 100-ms-long command voltage pulses were applied at the soma, with an amplitude $(30-35 \mathrm{mV})$ set just below the spike-generation threshold. Where required, a $2 \mathrm{~ms}$ spikegenerating pulse was also applied 30 or $50 \mathrm{~ms}$ after the depolarization onset. In the presence of $1 \mu \mathrm{M}$ TTX, the pulse amplitude was $100 \mathrm{mV}$.

The $\mathrm{Ca}^{2+}$-dependent fluorescence response $\Delta F / F$ (space integrated over the visible bouton width) was routinely calculated as $\left(F_{\text {post }}-F_{\text {pre }}\right) /$
$\left(F_{\text {pre }}-F_{0}\right)$, where $F_{0}$ denotes the background fluorescence measured outside any cell structures filled with the indicator. Because special care was taken to avoid escape of the dye from the pipette and because the site of imaging was normally at a significant distance from the pipette tip, $F_{0}$ was likely to represent the average photomultiplier tube dark current (the background fluorescence levels outside and inside the slice were indistinguishable). In the case of subthreshold depolarization pulses, $F_{\text {pre }}$ and $F_{\text {post }}$ represented the line-scan fluorescence averaged over, respectively, $200 \mathrm{~ms}$ before the pulse onset and $100 \mathrm{~ms}$ after the onset. In the case of spike generation ( 30 or $50 \mathrm{~ms}$ into the $100 \mathrm{~ms}$ long depolarization pulse), $F_{\text {pre }}$ and $F_{\text {post }}$ were taken, respectively, over the time intervals $50 \mathrm{~ms}$ before and $50 \mathrm{~ms}$ after the spike onset. Recordings were routinely collected in a cycle of three alternating sweeps: no depolarization; depolarization pulse; depolarization pulse plus spike generation. This experimental design allowed within-duty-cycle comparisons, minimizing time-dependent trends in the measured variable. Image analysis was performed on stacks of stored line-scan images using NIH Image macros. False color tables and averaged images were used for illustration purposes, but the quantitative analyses always dealt with the original (gray level) pixel brightness values. In most experiments, we reconstructed the axon trajectory using a collage of high-resolution Kalman-filtered $z$-stacks 15-20 $\mu \mathrm{m}$ deep using 10-scan average frames.

Translating steady-state fluorescence changes into $\mathrm{Ca}^{2+}$ concentration changes. Classically, the steady-state $\mathrm{Ca}^{2+}$ concentration $\left[\mathrm{Ca}^{2+}\right]_{\mathrm{ss}}$ can be estimated from the $\mathrm{Ca}^{2+}$ indicator fluorescence $\mathrm{F}$ using the following relationship:

$$
\frac{\left[\mathrm{Ca}^{2+}\right]_{s s}}{K_{d}}=\frac{F-F_{\min }}{F_{\max }-F},
$$

where $K_{\mathrm{d}}$ is the $\mathrm{Ca}^{2+}$ indicator dissociation constant, and $F_{\max }$ and $F_{\min }$ represent the maximum (saturated) and $\mathrm{Ca}^{2+}$-independent (residual) fluorescence of the indicator, respectively. To adopt the experimentally measured quantities, Equation 1 can be recast as follows (Scott and Rusakov, 2006): 
A

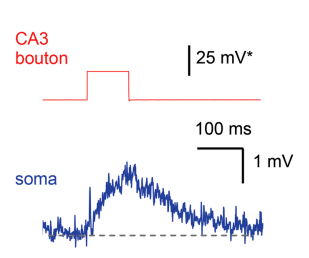

B

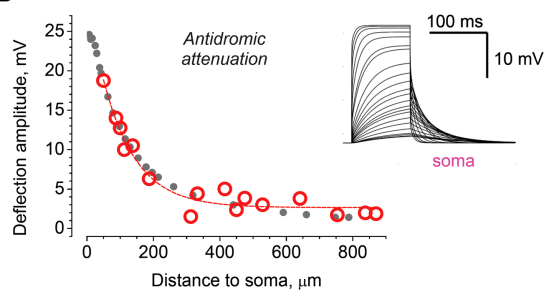

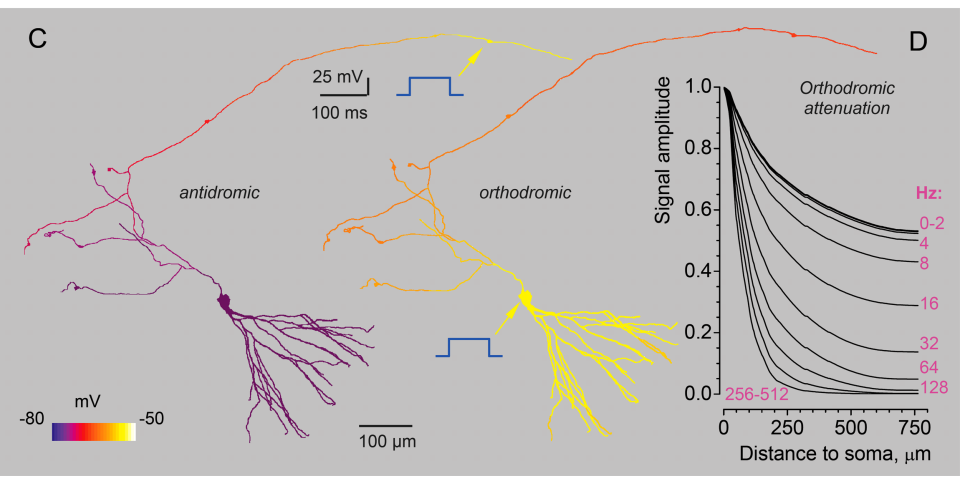

Figure 2. Subthreshold depolarization propagates in intact MFs between remote boutons and granule cell somata. $\boldsymbol{A}$, Example of a dual-patch experiment (Fig. 1) showing somatic voltage deflection (blue, eight-trial average; converted from whole-cell current recording using input resistance) evoked by a 100 ms depolarizing pulse at a CA3 MF bouton (red), with the amplitude adjusted just below a spiking threshold; the latter was established earlier to be $\sim+25 \mathrm{mV}$ relative to the resting potential at these boutons (Geiger and Jonas, 2000). B, Antidromic (axon-soma) attenuation of a subthreshold depolarization wave in individual MFs: experimental data and theoretical estimates. Ordinate, Amplitude of somatic current deflection evoked by nearthreshold depolarization ( $100 \mathrm{~ms} / 25 \mathrm{mV}$ ) of axonal boutons (as in $A$ ); abscissa, soma- bouton distance. Red open circles, Data of dual-patch recordings (as in $\boldsymbol{A}$ ); dotted line, the best fit with a single-exponent decay. Gray dots, Best-fit data obtained in simulation experiments mimicking dual-patch recordings in a detailed NEURON model of a granule cell (Schmidt-Hieber et al., 2007); optimization was achieved by adjusting the cable properties of the reconstructed axon, as detailed below in $\boldsymbol{C}$. Inset, Simulated traces of somatic $V_{m}$ in response to axonal subthreshold depolarization pulses at axon-soma distances shown in the plot. C, Testing axonal attenuation using a NEURON model of a fully reconstructed dentate granule cell adapted from (SchmidtHieber et al., 2007) (cell number 7, imported from SenseLab; ModelDB accession number 95960, http://senselab.med.yale.edu/ modeldb). Left, A simulation example: antidromic (axon-soma) attenuation of the $100 \mathrm{~ms} / 25 \mathrm{mV}$ depolarization applied at the axonal site marked by a yellow arrow (resting $V_{\mathrm{m}}=-80 \mathrm{mV}$; false color scale, membrane voltage). The depolarization site was systematically changed and the (unknown) axonal properties were adjusted to obtain best fit for the experimental data, as shown in $\boldsymbol{B}$, yielding intracellular resistivity $R_{\mathrm{i}} \approx 50 \Omega \cdot \mathrm{cm}$ and specific membrane resistance $R_{\mathrm{m}} \approx 36.4 \mathrm{k} \Omega \cdot \mathrm{cm}^{2}$ (membrane capacitance, $C_{\mathrm{m}} \approx 1 \mu \mathrm{F} / \mathrm{cm}^{2}$, and axon morphology were kept unchanged). Right, The best-fit model tested for orthodromic (soma-axon) attenuation in response to a square pulse, as shown; a simulation example. In the resulting model, the steady-state input resistance of MF boutons was $1.3-2.7 \mathrm{G} \Omega$ for distances from the soma ranging between 350 and $700 \mu \mathrm{m}$, respectively. $\boldsymbol{D}$, Summary of simulation experiments: orthodromic attenuation of signal harmonics (frequency indicated) along the axon. where the parameter values measured previously are as follows. In Fluo-4 $\left(K_{d} \sim 350 \mathrm{nM}\right.$ ) experiments, $R_{\mathrm{ct}} / F_{\max }=0.237$ (relative contribution of Alexa cross-talk fluorescence to the $\mathrm{Ca}^{2+}$ channel emission signal), and $F / F_{\max }=0.380, F_{\min } / F_{\max } \approx 0$ (Scott and Rusakov, 2006); in OGB-1 $\left(K_{d}\right.$ $\sim 200 \mathrm{nM}$ ) experiments, $R_{\mathrm{ct}}=0, F / F_{\max }=0.465$, and $F_{\min } / F_{\max }=0.167$ (Maravall et al., 2000; Jackson and Redman, 2003; Oertner and Matus, 2005; Scott and Rusakov, 2006). These data imply the following empirical relationships between a relative fluorescence change $F / F_{\text {rest }}\left(F_{\text {rest }}\right.$ is the fluorescence at the resting $\mathrm{Ca}^{2+}$ concentration $\left[\mathrm{Ca}^{2+}\right]_{\text {rest }}$ ) and a relative $\mathrm{Ca}^{2+}$ concentration change $\left[\mathrm{Ca}^{2+}\right] /\left[\mathrm{Ca}^{2+}\right]_{\text {rest }}$ in the subthreshold depolarization experiments:

$$
\frac{\left[\mathrm{Ca}^{2+}\right]}{\left[\mathrm{Ca}^{2+}\right]_{\text {rest }}}=4.348 \frac{0.38 F / F_{\text {rest }}-0.237}{1-0.38 F / F_{\text {rest }}}
$$

for Fluo-4 fluorescence, and

$$
\frac{\left[\mathrm{Ca}^{2+}\right]}{\left[\mathrm{Ca}^{2+}\right]_{\text {rest }}}=1.795 \frac{0.465 F / F_{\text {rest }}-0.167}{1-0.465 F / F_{\text {rest }}}
$$

for OGB-1 fluorescence. The Equations 3 and 4 indicate that a fractional increase in fluorescence, at least up to $\sim 50 \%$ of the resting level, should reflect an increase in the steady-state $\mathrm{Ca}^{2+}$ level with a power exponent of three. These expressions were thus applied to evaluate changes in $\mathrm{Ca}^{2+}$ concentration induced by subthreshold depolarization.

Translating spike-evoked fluorescence transients into the total $\mathrm{Ca}^{2+}$ entry. A different approach was required to translate fractional changes of the spike-evoked presynaptic $\mathrm{Ca}^{2+}$ fluorescence signals (evoked $\Delta F / F$ ) into the corresponding fractional change of rapid (nonstationary) $\mathrm{Ca}^{2+}$ entry. This calibration was performed using an explicit singlecompartmental model (Scott and Rusakov, 2006): an increase in $\Delta F / F$ was matched by the model outcome in which the unknown actionpotential-evoked total $\mathrm{Ca}^{2+}$ entry (in molar) was a single adjustable parameter, whereas the rest of the parameters (concentration and kinetics of the $\mathrm{Ca}^{2+}$ indicator, of the endogenous $\mathrm{Ca}^{2+}$ buffer calbindin-28K, $\mathrm{Ca}^{2+}$ removal rate, and the resting $\mathrm{Ca}^{2+}$ level) were obtained experimentally, as documented previously (Scott and Rusakov, 2006). Supplemental Figure S2C (available at www.jneurosci.org as supplemental material) shows the results of these calculations for the experimental measurements of $\Delta F / F$ at five different external $\mathrm{Ca}^{2+}$ concentrations.

Bulk loading of cell-permeable BAPTA AM (testing the consequences of $\mathrm{Ca}^{2+}$ buffering for depolarization- or high- $\left[\mathrm{K}^{+}\right]_{o^{-}}$induced facilitation). BAPTA AM was initially dissolved in DMSO and diluted in the recording bath solution to a final concentration of $200 \mu \mathrm{M}$. Slice incubation with BAPTA AM for 10-15 min led to a substantial reduction of EPSCs in the postsynaptic CA3 pyramidal cells and of the action-potential-induced $\mathrm{Ca}^{2+}$ transients in granule cell dendrites and axons (see Fig. 6), implying accumulation of the buffer in the cytosol. We subsequently washed out BAPTA AM remaining in the extracellular space. Special care was taken to wash thoroughly the entire perfusion system and recording chamber before and after such experiments.

Sensitivity and statistical power of $\mathrm{Ca}^{2+}$-imaging experiments. Before attempting to detect (small) changes in $\mathrm{Ca}^{2+}$-dependent fluorescence induced by subthreshold depolarization, we routinely checked that the imaged MF bouton showed a large action-potential-evoked $\mathrm{Ca}^{2+}$ signal (Scott and Rusakov, 2006). The accuracy of these experiments is potentially reduced by (1) the pixel noise (dark current) in individual line scans (trials), (2) the trial-to-trial measurement error in an individual bouton, and (3) variability among boutons. The pixel noise in the average linescan signal (8-10 trials per bouton) representing the baseline $\mathrm{Ca}^{2+}$ dependent fluorescence had a coefficient of variation $(\mathrm{CV})$ of $0.122 \pm$ $0.004(n=40)$. Because this noise is much faster than the expected fluctuations in $\mathrm{Ca}^{2+}$-dependent fluorescence in baseline conditions, for the fluorescence value averaged over a $100 \mathrm{~ms}$ sampling window $(500 \mathrm{~Hz}$ scanning) this $\mathrm{CV}$ is reduced to $0.122 / \sqrt{50}=0.0172$. This suggests that in a typical experiment ( $8-10$ trials), we should be able to detect a baseline fluorescence change $>2-3 \%$ [as illustrated by example traces in studies by Ruiz et al. (2003) and Scott and Rusakov (2006)]. This corresponds to either a 3-9\% change in steady-state $\mathrm{Ca}^{2+}$ increase (Eqs. 3, 4) or a $2-3 \%$ change in spike-evoked $\mathrm{Ca}^{2+}$ entry. Because we have typically repeated experiments in at least $n=4$ boutons, the corresponding sta- 
A

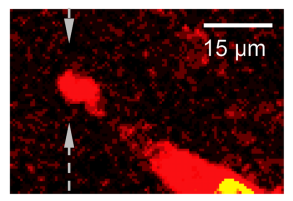

B

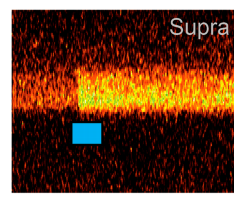

D

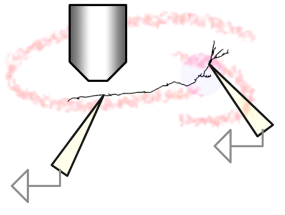

C

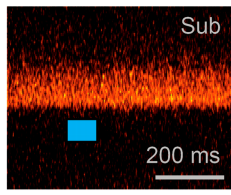

$\mathrm{E}$

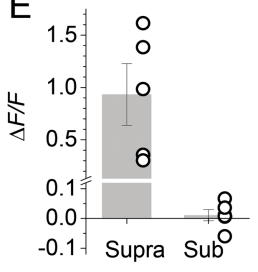

A

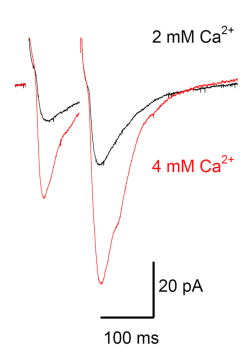

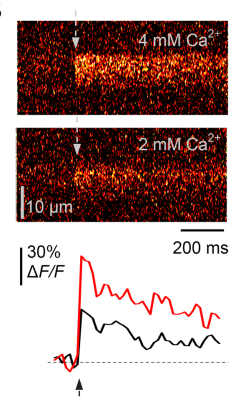

C Total $\mathrm{Ca}^{2+}$ entry, $\mu \mathrm{M}$

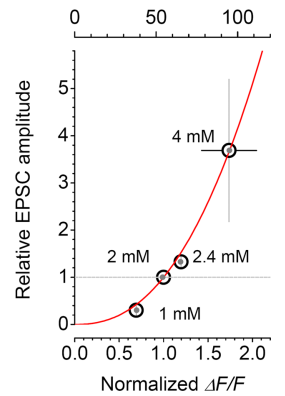

Figure 4. $\mathrm{Ca}^{2+}$ entry in MF giant boutons controls synaptic responses in CA3 pyramidal cells with a power relationship of $\sim 2.5$. A, Example traces of MF-evoked EPSCs in the same CA3 pyramidal cell (30 trace average) at $\left[\mathrm{Ca}^{2+}\right]_{0}=2 \mathrm{~mm}$ (black) and $4 \mathrm{~mm}$ (red). B, Presynaptic $\mathrm{Ca}^{2+}$ transients evoked by an action potential in the same giant MF bouton in area $\mathrm{CA3}$ (line scans, Fluo-4 channel; 10 trace average) at $\left[\mathrm{Ca}^{2+}\right]_{0}=4$ and $2 \mathrm{~mm}$, as indicated (bottom, black and red lines, respectively); dashed arrows indicate the action potential onset. C, Summary relationship $(n=16)$ between the $\Delta F / F$ signal (open circles), total calculated $\mathrm{Ca}^{2+}$ entry (gray dots), and EPSC amplitude (relative to the amplitude at $\left[\mathrm{Ca}^{2+}\right]_{0}=2 \mathrm{~mm}$ ) at different $\left[\mathrm{Ca}^{2+}\right]_{0}$ values, as indicated. Error bars indicate SEM; red line, the best-fit power relationship $y=A x^{B}$, where $B=2.5 \pm 0.2$ and $A$ is a scaling factor. For further details, see Materials and Methods and supplemental Figure $\$ 2$ (available at www.jneurosci.org as supplemental material). pulses (blue segments) applied to the bouton (black and red lines in $\boldsymbol{D}$, respectively; line-scan position shown in $A$ ). Subthreshold depolarization applied to the loose-patched bouton was simultaneously monitored as a voltage deflection at the soma, as shown in Figure $2 A$. $E$, Summary of dual-patch experiments showing average $\mathrm{Ca}^{2+}$-dependent fluorescence signals in response to suprathreshold and maximal subthreshold depolarization, as indicated (error bars indicate mean $\Delta F / F: 93 \pm 29 \%$ and $1.1 \pm 1.7 \% ; n=5$ and $n=6$, respectively; circles, individual data points).

tistical power should provide for detection of changes in baseline $\mathrm{Ca}^{2+}$ that are $\sim \sqrt{n}$ times smaller $(<2 \%)$.

Compartmental model of a dentate granule cell. We used a NEURON model of a fully reconstructed dentate granule cell adapted from the study by Schmidt-Hieber et al. (2007) (cell number 7, imported from SenseLab; ModelDB accession number 95960, http://senselab.med. yale.edu/modeldb). Depolarization pulses ( $100 \mathrm{~ms}, 25 \mathrm{mV}$ ) were applied at axonal sites at different distances from the cell soma while adjusting the axonal cable properties to match the antidromic attenuation documented in dual-patch experiments. The best fit yielded intracellular resistivity $R_{\mathrm{i}}$ and specific membrane resistance $R_{\mathrm{m}}$ for the cell axon, as described in Results. In the optimized model, the steady-state input resistance of MF boutons was 1.3-2.7 G $\Omega$ for distances from the soma ranging between, respectively, 350 and $700 \mu \mathrm{m}$; this was consistent with experimental values reported using whole-terminal recordings in giant MF boutons (Alle and Geiger, 2007).

Modeling the effects of EGTA on spatial cooperativity among presynaptic $\mathrm{Ca}^{2+}$ nanodomains in MF boutons. Simulations were implemented in Virtual Cell (VCell), version 4.2, at the National Resource for Cell Analysis and Modeling (University of Connecticut Health Center, Farmington, CT). A fragment of the presynaptic MF bouton was modeled as a truncated sphere (see Fig. 8) (diameter, $1 \mu \mathrm{m}$; a 0.2- $\mu \mathrm{m}$-high segment was cut off to represent a flat synaptic active zone). To investigate potential interactions among $\mathrm{Ca}^{2+}$ microdomains, individual $\mathrm{Ca}^{2+}$ sources (voltage-dependent channels) were distributed in nine 50-nm-wide clusters. In each cluster, $\mathrm{Ca}^{2+}$ influx followed action potential driven kinetics represented by a Gaussian with $\sigma=0.5 \mathrm{~ms}$ (Bischofberger et al., 2002) and an amplitude corresponding to the opening of nine channels letting through 125 ions each during an action potential (Koester and Sakmann, 2000). This arrangement was consistent with estimates of the $\mathrm{Ca}^{2+}$ channel distribution in the presynaptic membrane of central synapses ( $\mathrm{Li}$ et al., 2004).

The terminal contained the endogenous $\mathrm{Ca}^{2+}$ buffer prevalent at MF terminals, calbindin-28K, at a known total concentration of $160 \mu \mathrm{M}(40$ $\mu \mathrm{M} \times$ four binding sites; $k_{\text {on }}=3 \times 10^{7} \mathrm{M}^{-1} \mathrm{~s}^{-1} ; k_{\text {off }}=9.0 \mathrm{~s}^{-1}$ ) (Müller et al., 2005) with an effective diffusion coefficient of $2.5 \mu \mathrm{m}^{2} / \mathrm{s}$ and equilibrated with a resting $\mathrm{Ca}^{2+}$ concentration of $100 \mathrm{nM}$ (Scott and Rusakov, 2006). EGTA ( $10 \mathrm{~mm})$ was added $\left(k_{\text {on }}=10^{7} \mathrm{M}^{-1} \mathrm{~s}^{-1} ; k_{\text {off }}=0.7\right.$ $\mathrm{s}^{-1}$ ) to test its effects on the $\mathrm{Ca}^{2+}$ profile; for the initial conditions, the

quasi-equilibrated local $\mathrm{Ca}^{2+}$ concentration was decreased to $5 \mathrm{~nm}$. (The actual effective level of the $\mathrm{Ca}^{2+}$ concentration clamp by EGTA is not known and may depend on location-specific $\mathrm{Ca}^{2+}$ homeostasis mechanisms; this level, however, has no influence on the qualitative conclusions of these simulations.) Other simulation parameters were as follows: arena, $1.1 \times 1.0 \times 1.1 \mu \mathrm{m}$; cell size, $10 \times 10 \times 10 \mathrm{~nm}$ (total regular mesh $1.21 \times 10^{6}$ elements); time step, $50 \mu \mathrm{s}$.

Statistical tests. To test the difference between the sampled means, we routinely applied a two-tailed paired $t$ test (Gaussian data scatter) or a nonparameteric Wilcoxon test (non-Gaussian data scatter). The confidence intervals were calculated from the raw data samples using Statistica (StatSoft).

\section{Results}

Electrotonic propagation between giant boutons and the soma

We traced the axons (MFs) of individual granule cells to identify giant boutons synapsing in the CA3 region 500-1000 $\mu \mathrm{m}$ from the soma (Scott and Rusakov, 2006) (Fig. 1A,B). Because of the three-dimensional trajectory of MFs, the traced boutons generally occurred $>50 \mu \mathrm{m}$ deep in the slice, precluding routine whole-bouton recordings. In some cases, however, we obtained simultaneous loose-patch recordings from these boutons using a second pipette (Fig. 1C). We verified that individual action potentials evoked either at the soma or at the giant bouton reliably propagate in either direction with no failures, generating local presynaptic $\mathrm{Ca}^{2+}$ transients (Fig. $1 C-E$ ) (spike initiation in giant boutons using loose patch is consistent with a high local density of $\mathrm{Na}^{+}$channels) (Engel et al., 2001). Transient subthreshold depolarization of an individual bouton (100 ms current pulses, adjusted just below action potential threshold, which is $\sim 25 \mathrm{mV}$ above the resting membrane potential in these boutons) (Geiger and Jonas, 2000) evoked an inward current detected at the soma (Fig. 2A). We could therefore directly demonstrate electrotonic propagation in MFs over $>500 \mu \mathrm{m}$, which has previously only been shown with bulk depolarization of multiple granule cells (Alle and Geiger, 2006). Moving the pipette away from the bouton $2-10 \mu \mathrm{m}(n=10)$ completely eliminated both subthreshold and suprathreshold events at the soma, arguing against indirect effects mediated by neighboring structures. To estimate the electrotonic length constant for these depolarization waves propagating antridromically, we repeated dual-patch 
A

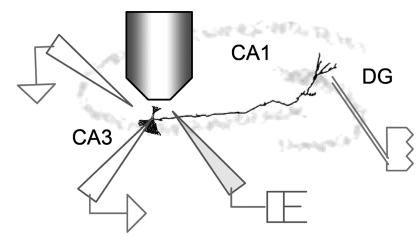

B
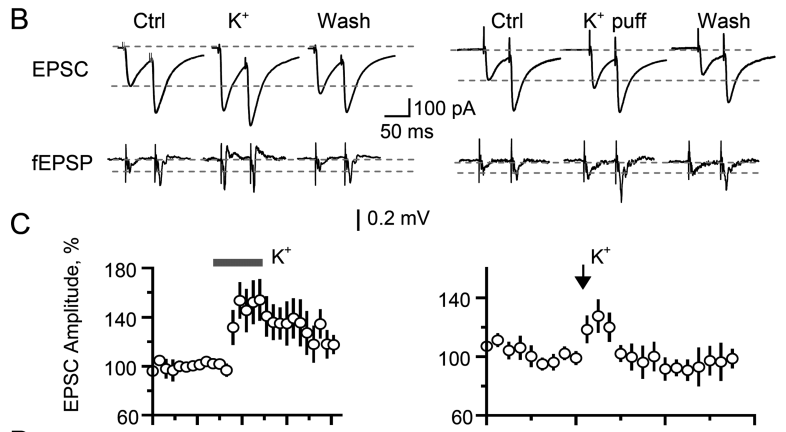

D

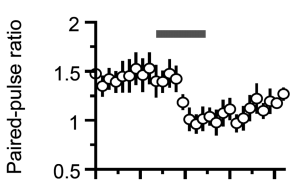

E

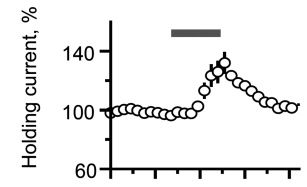

$\mathrm{F}$

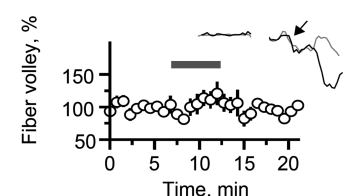

$0.2 \mathrm{mV}$
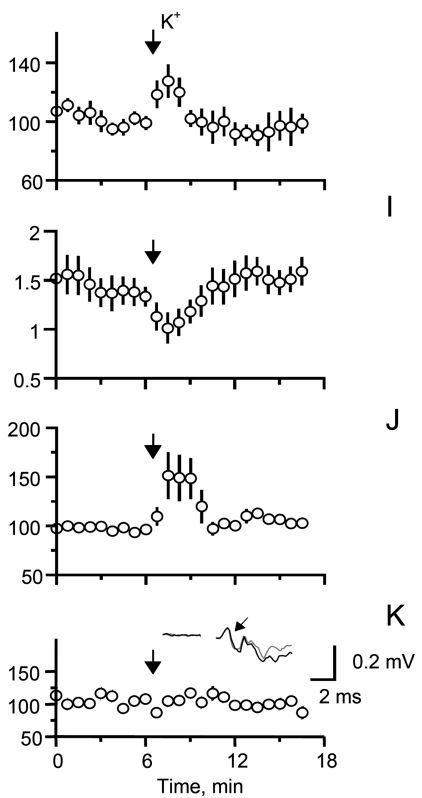

Figure 5. Presynaptic depolarization associated with raised $\left[\mathrm{K}^{+}\right]_{0}$ reversibly enhances the amplitude while decreasing the paired-pulse ratio of MF-evoked responses in CA3 pyramidal cells. $\boldsymbol{A}$, Schematic showing positions of the stimulating electrode (stratum granulosum), patch-clamp pipette (bottom left), the extracellular recording electrode (top left), and the pressure-pulse pipette (middle; $\sim 20 \mathrm{~mm} \mathrm{~K}^{+}$in bath solution). $\boldsymbol{B}$, Whole-cell EPSCs (top traces) and fEPSPs (bottom traces) recorded, respectively, in CA3 pyramidal cells and in stratum lucidum, evoked by two stimuli ( $25 \mathrm{~ms}$ apart) applied in the granule cell layer (one-cell example). Ctrl, Control conditions; $\mathrm{K}^{+},\left[\mathrm{K}^{+}\right]_{0}$ increased from $2.5-5 \mathrm{~mm}$; Wash, washout. $\boldsymbol{C}-\boldsymbol{F}$, The average time course of the first EPSC amplitude $\left(\boldsymbol{C}\right.$; average change in high $\left[\mathrm{K}^{+}\right]_{0^{\prime}}+54 \pm 15 \%$; $n=6 ; p<0.001)$, the paired-pulse amplitude ratio $(\boldsymbol{D} ;-31 \pm 8 \% ; p<0.03)$, holding current $(\boldsymbol{E} ;+24 \pm 13 \% ; p<0.05)$ and the fiber volley amplitude $[\boldsymbol{F} ;+15 \pm 13 \%$; not significant (NS)]. $\boldsymbol{F}$, Inset, A characteristic fEPSP trace showing a fiber volley (arrow) in control conditions (black) and after an increase in $\left[\mathrm{K}^{+}\right]_{0}$ (gray). $\boldsymbol{G} \boldsymbol{K}$, Same experiments as in $\boldsymbol{B}-\boldsymbol{F}$ but with pressure application of $\mathrm{K}^{+}(100 \mathrm{~ms} / \sim 5 \mathrm{psi}$ pulse; arrow) near the recorded CA3 pyramidal cell. Notation is as in $\boldsymbol{B}-\boldsymbol{F}$. The average changes after a high $\mathrm{K}^{+}$puff $(n=9)$ are as follows: EPSC amplitude, $+29 \pm 10 \%(p<0.03)$; paired-pulse ratio, $-29 \pm 8 \%(p<0.01)$; holding current, $+44 \pm 34 \%$ (NS); fiber volley, $-5 \pm 6 \%$ (NS). Error bars indicate SEM.

experiments in axonal boutons for different distances from the soma. In these measurements, cell input resistance values yielded a current-voltage conversion factor at the soma; assuming an axonal threshold depolarization of $\sim 25 \mathrm{mV}$ (see above), we translated the somatic current deflection directly to voltage attenuation in different cells. We thus could combine measurements in individual granule cells regardless of variability in input resistance, which depends strongly on the preservation of intact dendritic trees (supplemental Fig. S1, available at www.jneurosci.org as supplemental material). Fitting the entire data set with a simple exponential decay function

A

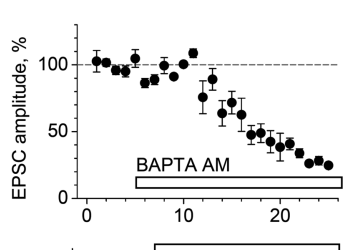

B
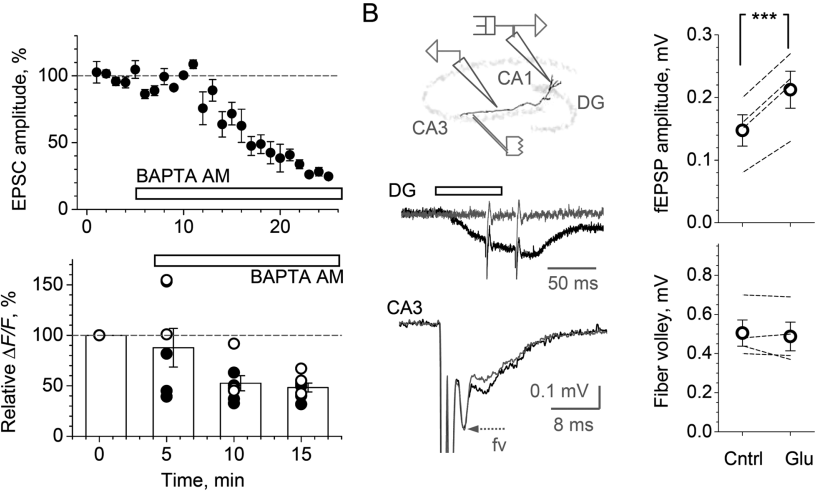

C
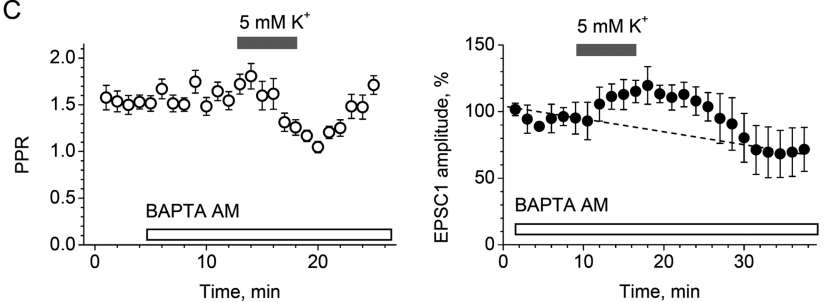

Figure 6. Depolarization-induced enhancement of MF-CA3 pyramidal cell transmission is not affected by high-affinity buffering of presynaptic $\mathrm{Ca}^{2+}$. A, Bulk-loading granule cells with the high-affinity $\mathrm{Ca}^{2+}$ buffer BAPTA AM reduces the MF-evoked EPSCs in CA3 pyramidal cells to $27 \pm 2 \%$ of baseline (top plot, mean $\pm \mathrm{SEM} ; n=3$ ) and action-potential-evoked $\Delta F / F$ responses to $48 \pm 4 \%$ of baseline (bottom plot; black and open circles denote recording from dendrites and axons, respectively; combined, $n=7$; imaged using $200 \mu \mathrm{m}$ Fluo-4; error bars indicate average values). $\boldsymbol{B}$, In the presence of bulk-loaded BAPTA AM (see $\boldsymbol{A}$ ), depolarizing granule cell somata with local puffs of glutamate enhances the fEPSPs evoked by stimulation of MFs in CA3, with no change in fiber recruitment. Top left, Experiment schematic: an extracellular patch-pipette electrode in the dentate gyrus (DG) filled with the bath medium and glutamate $(50 \mathrm{~mm})$ is also connected to the micropump pressure line. Top traces, Extracellular recordings in the DG during alternating sweeps, with or without glutamate puff (black and gray, respectively); during and after the puff (open bar), an inward current deflection reflecting somatic depolarization is prominent, and pop spikes are seen indicating antidromic excitation of granule cells by extracellular stimuli in CA3. Bottom traces, fEPSPs recorded simultaneously in stratum lucidum (time scale expanded); during the puff (black), the fEPSP amplitude increases with no changes in fiber volley (fv; in these experiments, fEPSPs are relatively small compared with fv because of a strongly reduced release probability in the presence of BAPTA). Plots, Statistical summary; open circles, average $\pm \mathrm{SEM} ; n=4$; dotted lines, data from the same experiment; ${ }^{* * *} p<0.005$. $C$, In the presence of cytosolic BAPTA (as in $A$ ), an increase in $\left[\mathrm{K}^{+}\right]_{0}$ still decreases PPR (left; $n=5$ ) and increases the amplitude (right; $n=4)$ of MF-evoked EPSCs in CA3 pyramidal cells (dotted line in the right plot indicates the amplitude reduction trend after bulk application of BAPTA AM; see $A$ ).

indicated a length constant of $99 \pm 14 \mu \mathrm{m}$ (including a $\sim 10 \%$ offset; $n=16$ ) (Fig. $2 B$ ).

To assess orthodromic attenuation of axonal depolarization based on these experimental data, we used a detailed NEURON model of a dentate granule cell with a mostly preserved axon (Schmidt-Hieber et al., 2007) (Materials and Methods). In this model, the authors fully reconstructed the granule cell morphology (including the axon) and exhaustively cross-tested cable properties of the dendrites. To assess the unknown cable parameters of the reconstructed axon, we reproduced our dual-patch experiments $(100 \mathrm{~ms} / 25 \mathrm{mV}$ axonal depolarization at different distances from the soma) in the model (Fig. 2C). The best-fit correspondence between our experiments and simulations was obtained when the axon had an intracellular resistivity $R_{\mathrm{i}} \approx 50 \Omega \cdot \mathrm{cm}$ and a specific membrane resistance $R_{\mathrm{m}} \approx 36.4 \mathrm{k} \Omega \cdot \mathrm{cm}^{-2}$ (Fig. $2 B, C$ ). Once the modeled cell was consistent with the experimental data, it allowed an estimate of the orthodromic attenuation of depo- 
larization propagating from the soma along the axon (Fig. 2C, right cell diagram). The results indicate that the depolarization wave could propagate for hundreds of micrometers depending on the carrying frequency that defines the signal waveform (Fig. 2D, standard harmonics are shown).

\section{Maximal subthreshold depolarization has no effect on $\mathrm{Ca}^{2+}$ in giant MF boutons}

In dual-patch experiments combined with presynaptic $\mathrm{Ca}^{2+} \mathrm{im}-$ aging, applying a local suprathreshold depolarization pulse to a giant bouton evoked a large spike-dependent presynaptic $\mathrm{Ca}^{2+}$ signal (average $\Delta F / F=93 \pm 29 \% ; p<0.001 ; n=5$ ) (Fig. $3 A, B)$. However, 100-ms-long depolarizations just below spike threshold had no detectable effect on $\mathrm{Ca}^{2+}$-dependent fluorescence: the mean $\Delta F / F$ averaged $>150 \mathrm{~ms}$ after the depolarization onset was $1.1 \pm 1.7 \%(n=6$ soma-bouton pairs; $p>0.9)$ (Fig. $3 C-E)$.

However, according to the classical high-power relationship between neurotransmitter release and presynaptic $\mathrm{Ca}^{2+}$, only a small increment in $\mathrm{Ca}^{2+}$ entry may be sufficient for a substantial enhancement of transmission. Previous reports have suggested that increasing presynaptic $\mathrm{Ca}^{2+}$ influx through either spike broadening or elevation of external $\mathrm{Ca}^{2+}$ could enhance MFCA3 pyramidal cell transmission with an apparent power of 2 or less (Regehr et al., 1994; Geiger and Jonas, 2000; Blatow et al., 2003; Mori-Kawakami et al., 2003). To test this more directly, we varied the extracellular $\mathrm{Ca}^{2+}$ concentration $\left(\left[\mathrm{Ca}^{2+}\right]_{0}\right)$ and recorded both action-potential-evoked $\mathrm{Ca}^{2+}$ entry in giant $\mathrm{MF}$ boutons and EPSCs in CA3 pyramidal cells (EPSCs evoked by paired pulses were recorded in similar conditions but with no $\mathrm{Ca}^{2+}$ indicators) (Fig. $4 A, B$ ). The results suggest a power relationship between the EPSC amplitude and the presynaptic $\mathrm{Ca}^{2+}$ signal with an exponent of $2.5 \pm 0.2$ (Fig. $4 C$; supplemental Fig. S2, available at www.jneurosci.org as supplemental material). Translating $\mathrm{Ca}^{2+}$ fluorescence signals into total $\mathrm{Ca}^{2+}$ entry using a compartmental model calibrated previously (Scott and Rusakov, 2006) yielded a very similar relationship (Fig. 4C; supplemental Fig. S2C, available at www.jneurosci.org as supplemental material).

\section{Presynaptic depolarization sufficient to enhance transmitter} release has no effect on $\mathrm{Ca}^{2+}$ signaling at giant $\mathrm{MF}$ boutons In the above experiments, $\left[\mathrm{Ca}^{2+}\right]_{\mathrm{o}}$-dependent changes in total $\mathrm{Ca}^{2+}$ entry reflect an average change in $\mathrm{Ca}^{2+}$ influx through individual $\mathrm{Ca}^{2+}$ channels, including those immediately involved in neurotransmitter release. Therefore, the reported $43 \%$ enhancement of transmission by presynaptic depolarization (Alle and Geiger, 2006) could be explained by a $\sim 15 \%$ increase in $\mathrm{Ca}^{2+}$ sources near release sites. However, subthreshold depolarization in these boutons has no effect on the presynaptic $\mathrm{Ca}^{2+}$ current recorded under conditions giving a high signal-to-noise ratio (Alle and Geiger, 2006). Hence, the $15 \% \mathrm{Ca}^{2+}$ source increase, if such occurs, could be provided either by a change in the resting $\mathrm{Ca}^{2+}$ level or by release from intracellular $\mathrm{Ca}^{2+}$ stores. An increase in the resting $\mathrm{Ca}^{2+}$ concentration (over a depolarization period lasting tens of milliseconds) is very likely to spread throughout the bouton; the bouton-average $\mathrm{Ca}^{2+}$-dependent fluorescence should therefore be sufficiently sensitive to detect its consequences. However, $\mathrm{Ca}^{2+}$ store signaling might in principle be localized to the release-triggering sites and therefore missed by volume-average $\mathrm{Ca}^{2+}$ measurements. To test whether highly localized $\mathrm{Ca}^{2+}$ signals could explain the facilitatory effects of presynaptic depolarization, we turned to an alternative approach.

It was shown previously that depolarizing MFs by raising the
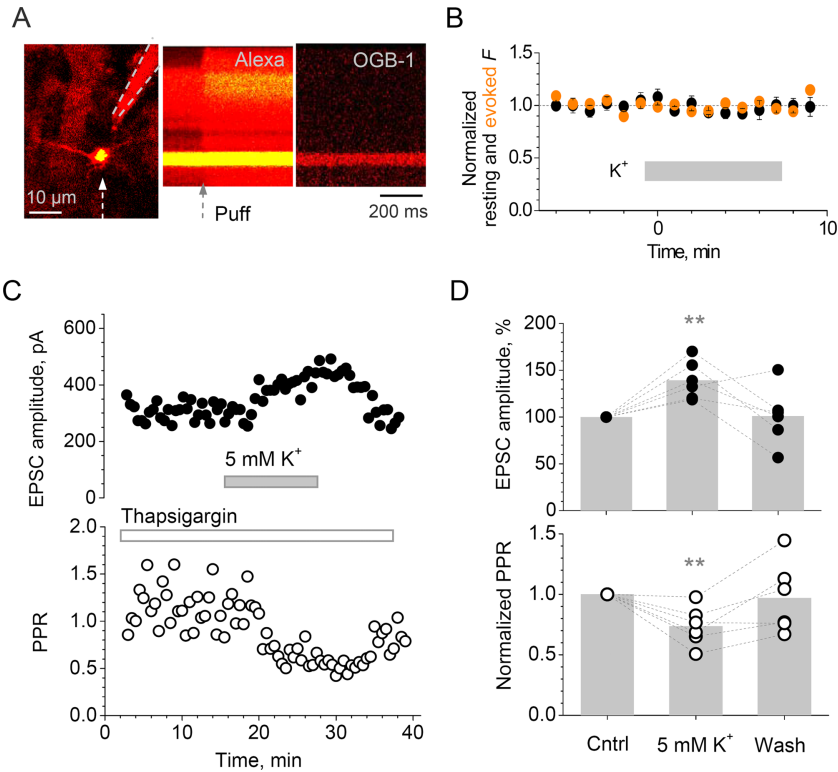

D

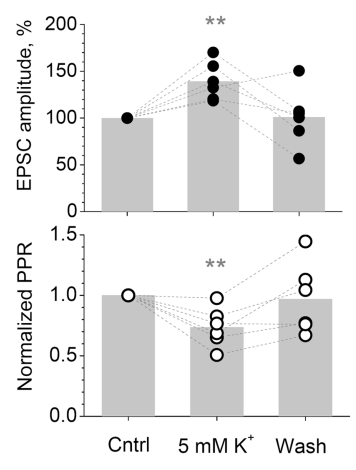

Figure 7. MF depolarization associated with raised $\left[\mathrm{K}^{+}\right]_{0}$ enhances transmission to $\mathrm{CA3}$ pyramidal cells with no changes in presynaptic $\mathrm{Ca}^{2+}$ and no contribution from $\mathrm{Ca}^{2+}$ stores. $\boldsymbol{A}$, Local increases in $\left[\mathrm{K}^{+}\right]_{0}$ have no effect on the resting $\mathrm{Ca}^{2+}$ level in individual giant MF boutons traced from granule cells; a characteristic one-bouton example. Left, A bouton is approached by a pressure application pipette (dotted lines; pipette medium, $30 \mathrm{~mm} \mathrm{KCl} \mathrm{plus} \mathrm{bath} \mathrm{medium} \mathrm{plus}$ $20 \mu \mathrm{m}$ Alexa Fluor 594; Alexa channel; arrow, line-scan position). Middle, Line scan (Alexa) illustrating the ejection flux profile (the brightness change front; no apparent mechanical disturbance can be seen in the bouton trace). Right, Line scan (OGB-1 channel) showing no detectable changes in the $\mathrm{Ca}^{2+}$-dependent fluorescence during the $\left[\mathrm{K}^{+}\right]_{0}$ rise. $\boldsymbol{B}$, Summary. Increases in $\left[\mathrm{K}^{+}\right]_{0}$ have no effect on either resting or evoked $\mathrm{Ca}^{2+}$ signals in giant MF boutons. Black circles, Resting $\mathrm{Ca}^{2+}$ fluorescence (average change in high $\left[\mathrm{K}^{+}\right]_{0}, 1.0 \pm 4.1 \% ; n=4$ ); orange circles, spike-evoked $\Delta F / F \mathrm{Ca}^{2+}$ signal $(-1.2 \pm 2.9 \%, n=3$ ) (for an example of recordings, see in Fig. $3 A, B$ ). Error bars indicate SEM. $C$, Increasing $\left[\mathrm{K}^{+}\right]_{0}$ to $5 \mathrm{~mm}$ in the presence of the $\mathrm{Ca}^{2+}$ store blocker thapsigargin reversibly reduces the PPR while increasing the amplitude of EPSCs in CA3 pyramidal cells (top and bottom plots, respectively); one-cell example. D, Summary of experiments in C: dotted lines connect data points from individual cells ( $n=$ 6; normalized to control values); bars, values averaged over the 5 min periods of control (Cntrl), increased $\left[\mathrm{K}^{+}\right]_{0}\left(5 \mathrm{mM} \mathrm{K}^{+}\right)$, and washout (Wash), as indicated. ${ }^{* *} p<0.01$.

extracellular $\mathrm{K}^{+}$concentration $\left[\mathrm{K}^{+}\right]_{\mathrm{o}}$ enhances EPSCs recorded in CA3 pyramidal cells with little change in fiber excitability (Schmitz et al., 2001). Although this was originally suggested to reflect a change in action-potential-dependent presynaptic $\mathrm{Ca}^{2+}$ entry (Schmitz et al., 2001), later experiments demonstrated that increasing $\left[\mathrm{K}^{+}\right]_{\mathrm{o}}$ up to $6.5 \mathrm{~mm}$ has no effect on the action potential waveform recorded in giant MF boutons (Alle and Geiger, 2006). We therefore first confirmed that raising $\left[\mathrm{K}^{+}\right]_{\mathrm{o}}$ from 2.5 to $5 \mathrm{~mm}$ increased EPSCs in CA3 pyramidal cells (by $53 \pm 15 \%$; $p<0.005 ; n=6)$, and that this was accompanied by a decrease in the paired-pulse ratio (PPR) $(31 \pm 8 \%$; $p<0.03)$ consistent with an increase in neurotransmitter release probability (Fig. $5 A-E$ ); changes in axon recruitment in high $\mathrm{K}^{+}$were too small to account for this result (Fig. 5F). Qualitatively identical results were obtained by locally and transiently increasing $\mathrm{K}^{+}$via pressure application (20-30 $\mathrm{mm} \mathrm{KCl}$ in perfusion medium, $100 \mathrm{~ms} / \sim 5$ psi) in area CA3 and far from the stimulus site, with no detectable effects on fiber recruitment (Fig. 5G-K).

If increases in local $\mathrm{Ca}^{2+}$ sources are responsible for depolarization-dependent enhancement of transmission, highaffinity $\mathrm{Ca}^{2+}$ buffering should suppress this phenomenon (Blatow et al., 2003; Burnashev and Rozov, 2005). Previously, testing a similar hypothesis by loading individual giant MF boutons with the $\mathrm{Ca}^{2+}$ chelator EGTA in whole-cell mode failed to abolish the 

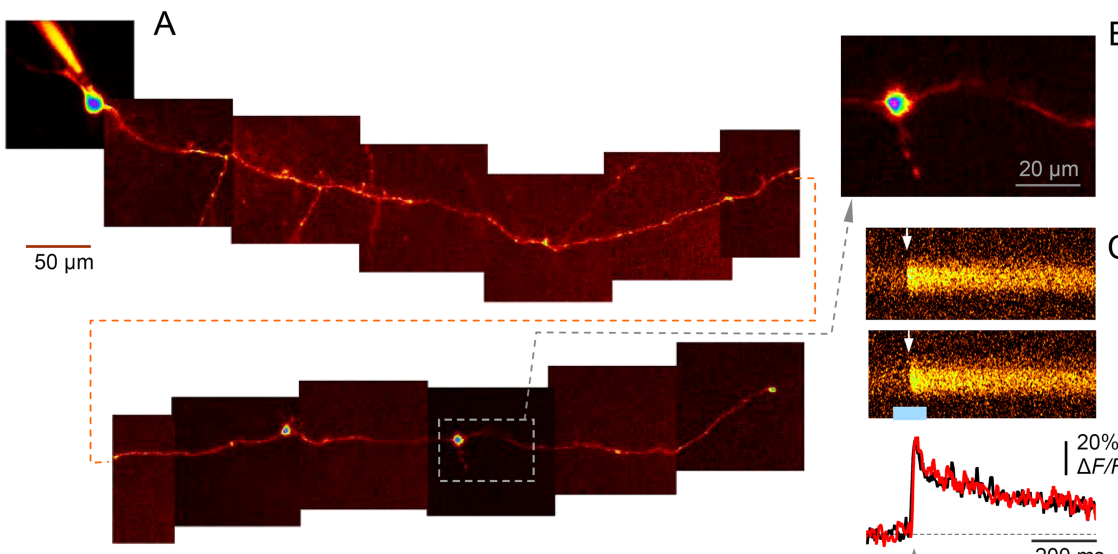

D

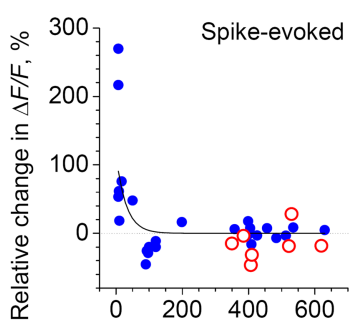

E

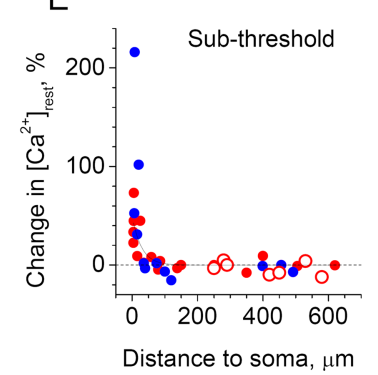

$\mathrm{F}$

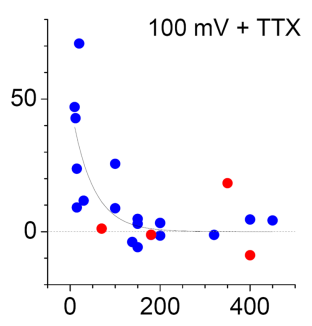

Figure 8. Somatic depolarization affects $\mathrm{Ca}^{2+}$ signaling only in proximal segments of granule cell axons. $A, B$, An example of tracing and identifying a giant $\mathrm{C} A 3$ bouton, with morphological reconstruction of the axon for soma-bouton distance measurements (Alexa channel). Two contiguous parts of the collage are connected by a yellow dotted line. The bouton of interest is shown by a gray rectangle and, at higher magnification, in $\boldsymbol{B}$. C, A characteristic example illustrating no change in spike-evoked $\mathrm{Ca}^{2+}$ entry in a giant $C A 3$ bouton (top line scan; plot, black trace) in response to somatic depolarization (bottom line scan; plot, red trace); blue segment, somatic depolarization from -80 to $-45 \mathrm{mV}$; arrows, action potential onset. See additional examples in supplemental Fig. S3 (available at www.jneurosci.org as supplemental material). D-F, Effect of subthreshold somatic depolarization (100 ms pulse, $30-35 \mathrm{mV}$ above the resting membrane potential) on presynaptic action-potential-evoked $\mathrm{Ca}^{2+}$ signals $(\boldsymbol{D})$ and on the resting $\mathrm{Ca}^{2+}$-dependent fluorescence $(\boldsymbol{E})$ decays rapidly along the axon; data in $\boldsymbol{F}$ show a similar effect of $100 \mathrm{mV}$, $200 \mathrm{~ms}$ somatic depolarization in the presence of $1 \mu \mathrm{M}$ TTX. Abscissa, Distance to the soma; ordinate, relative changes in $\Delta F / F$ signal $(\boldsymbol{D})$ or in the steady-state $\left[\mathrm{Ca}^{2+}\right]$ calculated from fluorescence changes $(\boldsymbol{E}, \boldsymbol{F})$ (supplemental Fig. S3, available at www.jneurosci.org as supplemental material) (see Material and Methods for details). Blue and red circles, Fluo-4 and OGB-1 data, respectively; open circles, data obtained at $33-35^{\circ} \mathrm{C}$; lines, a monoexponential fit.

facilitatory effect (Alle and Geiger, 2006). We therefore bulkloaded MFs with the high-affinity (cell-permeable) $\mathrm{Ca}^{2+}$ chelator BAPTA AM to an intracellular level sufficient to decrease EPSCs in CA3 pyramidal cells to $27 \pm 2 \%$ of baseline $(n=3)$ and action-potential-evoked $\Delta F / F$ responses (monitored with Fluo- 4$)$ to $48 \pm 4 \%$ of baseline $(n=6)$ (Fig. $6 A$ ) (these decreases were comparable with the effect of terminal loaded BAPTA in neocortical cells at a concentration of 0.5-1.0 mM) (Blatow et al., 2003). We next tested whether, in these conditions, somatic depolarization of dentate granule cells still enhances MF-CA3 pyramidal cell transmission: we excited MFs antidromically, with an extracellular electrode placed in area CA3, and monitored the corresponding field EPSPs (fEPSPs). Control trials were interleaved with trials where granule cell somata were depolarized by applying brief pulses of glutamate locally in the dentate gyrus (Fig. 6B, schematic). Glutamate application induced a transient negative deflection in the dentate gyrus but not in CA3 (Fig. $6 B$, traces). However, it significantly increased the fEPSC amplitude (by $47 \pm 6 \% ; n=4 ; p<0.005$ ), with no effect on the fiber volley in CA3 (change, $-4 \pm 4 \%$ ) (Fig. $6 B$ ) (in these experiments, the PPR was not measured because the effect of glutamate did not necessarily remain constant between stimuli). Consistent with these observations, in separate experiments, high $\mathrm{K}^{+}$reversibly enhanced MF-evoked EPSCs in CA3 pyramidal cells while reducing the corresponding PPR in the presence of intracellular BAPTA (Fig. 6C). Together, these results confirm that depolarization-dependent enhancement of release remained unaffected by presynaptic $\mathrm{Ca}^{2+}$ buffering, arguing that the underlying mechanism is unlikely to involve local $\mathrm{Ca}^{2+}$ sources and is not affected by $\mathrm{Ca}^{2+}$ indicators.

In agreement with these results, increasing $\left[\mathrm{K}^{+}\right]_{\mathrm{o}}$ had no effect on either evoked or resting $\mathrm{Ca}^{2+}$ signals in individual CA3 MF boutons (average change, $-0.8 \pm 3.0 \%$ and $0.4 \pm 3.3 \%$, respectively; $n=4 ; p>0.8$ ) (Fig. $7 A, B)$. Finally, depolarization-induced facilitation also remained intact in the presence of the $\mathrm{Ca}^{2+}$ store blocker thapsigargin (Fig. $7 C, D$ ) (in these conditions, thapsigargin on its own produces a slight increase in the resting $\mathrm{Ca}^{2+}$ level in these boutons) (Scott and Rusakov, 2006). This result further argues against the involvement of $\mathrm{Ca}^{2+}$ stores in the phenomenon.

\section{Somatic depolarization affects presynaptic $\mathrm{Ca}^{2+}$ only in proximal segments of the axon}

How can we reconcile the voltage insensitivity of presynaptic $\mathrm{Ca}^{2+}$ in giant boutons with the effects of depolarization in proximal axons (Ruiz et al., 2003)? We found that $100 \mathrm{~ms}$ somatic depolarization before evoking an action potential did affect axonal $\mathrm{Ca}^{2+}$ transients, but this influence diminished rapidly with distance, with a length constant of $37 \pm 17 \mu \mathrm{m}(n=28)$ (Fig. 8A-D; supplemental Fig. S3, available at www.jneurosci.org as supplemental material). The increase in resting $\mathrm{Ca}^{2+}$ in response to subthreshold depolarization also diminished systematically with distance, with a length constant of the same order $(29 \pm 13 \mu \mathrm{m} ; n=35)$ (Fig. $8 E$ ). The length constant was also similar ( $47 \pm 24 \mu \mathrm{m} ; n=$ 23) when $100 \mathrm{mV}, 200 \mathrm{~ms}$ depolarizing pulses were delivered in the presence of $1 \mu \mathrm{M}$ TTX to block action potentials (Fig. $8 F$ ). Indeed, in boutons occurring $>200 \mu \mathrm{m}$ from the soma, depolarization evoked no increase in spike-evoked or baseline $\mathrm{Ca}^{2+}$ signals: the average change was $-4.2 \pm 4.8 \%(n=17 ; p>0.50)$ and $-0.4 \pm 1.4 \%(n=23 ; p>0.77$; subthreshold and TTX data combined), respectively. These length constants are an order of magnitude smaller than those for electronic propagation of depolarization (see above), suggesting a sensitivity threshold for the effect of voltage on $\mathrm{Ca}^{2+}$ signaling. They are also substantially shorter than the length constants of long-term (minutes) effects of depolarization on $\mathrm{Ca}^{2+}$ signaling reported previously (Ruiz et al., 2003; Scott and Rusakov, 2006). This discrepancy between brief and long-lasting depolarizations may be explained by timeand voltage-dependent inactivation of axonal ion channels that modulate spike-driven $\mathrm{Ca}^{2+}$ entry. In addition, the difference in the voltage sensitivity of $\mathrm{Ca}^{2+}$ signaling between proximal and CA3 boutons might reflect differences in the expression of $\mathrm{Ca}^{2+}$ permeable channels between the two areas. 

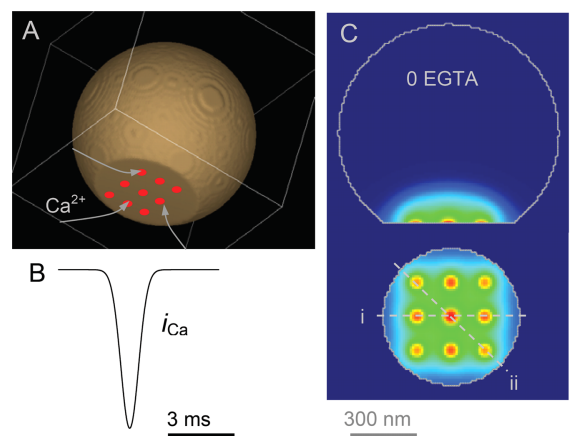

$300 \mathrm{~nm}$

E

E i

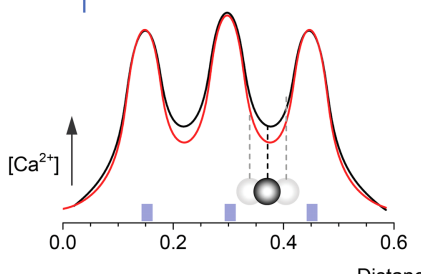

Distance, $\mu \mathrm{m}$

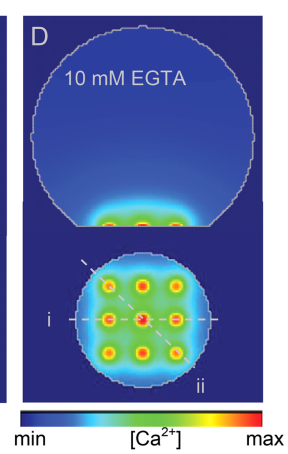

0 EGTA

ii

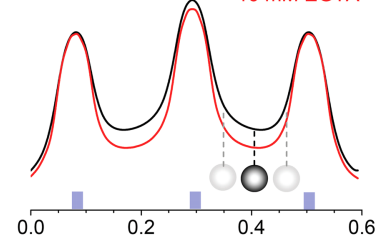

0.6

Figure 9. Simulations predict that $\mathrm{Ca}^{2+}$ chelation (with EGTA) reduces spatial cooperativity among presynaptic $\mathrm{Ca}^{2+}$ nanodomains. $\boldsymbol{A}, \boldsymbol{B}, \mathrm{A}$ three-dimensional (spherical) fragment of the modeled presynaptic bouton ( $\boldsymbol{A}$; diameter, $1 \mu \mathrm{m} ; 0.2 \mu \mathrm{m}$ segment truncated). Individual $\mathrm{Ca}^{2+}$ sources (voltage-dependent channels) were distributed in nine 50-nm-wide clusters, as depicted. In each cluster, $\mathrm{Ca}^{2+}$ influx followed the action-potential-driven kinetics $(\boldsymbol{B})$ and an amplitude corresponding to the opening of nine channels letting through 125 ions each during an action potential (Koester and Sakmann, 2000). Bouton geometry or the size of channel clusters has little impact on the qualitative conclusion of these simulations. For additional parameters, see Materials and Methods. C, D, A simulation snapshot of the free $\mathrm{Ca}^{2+}$ concentration profile at the peak of action-potential-evoked $\mathrm{Ca}^{2+}$ influx in the plane normal (central cross-section; top) and parallel (the first $10 \mathrm{~nm}$ layer inside the terminal; bottom) to the synaptic membrane, before and after adding $10 \mathrm{~mm}$ EGTA ( $\boldsymbol{C}, \boldsymbol{D}$, respectively). False color scale, Relative concentrations. $\boldsymbol{E}$, Simulated near-membrane $\mathrm{Ca}^{2+}$ concentration landscape (relative values, scaled for comparison) showing spatial summation of $\mathrm{Ca}^{2+}$ domains generated by $\mathrm{Ca}^{2+}$ influx through $\mathrm{Ca}^{2+}$ channel clusters. Black and red lines, Before and after adding $10 \mathrm{~mm}$ EGTA, respectively. $\boldsymbol{i}$, ii, Left (i) and right (ii) panels show the profile taken, respectively, along lines i and ii depicted in $\boldsymbol{C}$ and $\boldsymbol{D}$. Vesicle diagram, Shortening the distance between the vesicle exocytosis trigger (gray spheres) and $\mathrm{Ca}^{2+}$ channels (blue rectangles) corresponds to a greater increase of $\mathrm{Ca}^{2+}$ concentration in the presence of EGTA (red lines) than without EGTA (black lines). For the underlying assumptions, see Materials and Methods.

\section{Discussion}

We have performed dual-patch recordings from axons and somata of dentate granule cells to document directly the long-range electrotonic propagation of subthreshold depolarization in individual intact MFs. Such depolarization has been shown to facilitate MF-CA3 pyramidal cell transmission, with no detectable changes in spike-evoked presynaptic $\mathrm{Ca}^{2+}$ currents (Alle and Geiger, 2006). In the present study, we asked whether the underlying mechanism relied instead on $\mathrm{Ca}^{2+}$ signaling from $\mathrm{Ca}^{2+}$ stores or on changes in the resting $\mathrm{Ca}^{2+}$ level. We observed no change in resting or action-potential-evoked $\mathrm{Ca}^{2+}$ fluorescence in giant MF boutons, with either local, somatic, or high- $\left[\mathrm{K}^{+}\right]_{\mathrm{O}^{-}}$ induced depolarization (Figs. 3, 7, 8), although such manipulations should be sufficient to enhance MF-evoked EPSCs in CA3 pyramidal neurons (Figs. 5-7) and alter $\mathrm{Ca}^{2+}$ signaling in proximal segments of the axon (Fig. 8).

We have established that postsynaptic responses in CA3 pyramidal cells vary with presynaptic $\mathrm{Ca}^{2+}$ entry in giant $\mathrm{MF}$ boutons (and the corresponding fluorescence $\Delta F / F$ signal) with a power exponent of $\sim 2.5$ (Fig. 4 ). Such a dependence is slightly steeper than the power relationship between the EPSC amplitude and
$\left[\mathrm{Ca}^{2+}\right]_{\mathrm{o}}$ assessed here (Fig. 4; supplemental Fig. S2, available at www.jneurosci.org as supplemental material) or in previous studies (Regehr et al., 1994; Geiger and Jonas, 2000; Blatow et al., 2003; Mori-Kawakami et al., 2003). This suggests that presynaptic $\mathrm{Ca}^{2+}$ influx in MFs depends on $\left[\mathrm{Ca}^{2+}\right]_{\mathrm{o}}$ in a slightly sublinear manner, which is consistent with classical $\mathrm{Ca}^{2+}$ channel properties at this range of $\left[\mathrm{Ca}^{2+}\right]_{\mathrm{o}}$ (Tsien et al., 1987). In contrast, a recent study reported a power relationship of 3.8 (Gundlfinger et al., 2007) based on $\mathrm{Ca}^{2+}$ imaging of MFs bulk-loaded with the cell-permeable indicator Oregon Green BAPTA-1 AM $\left(K_{d} \sim 150\right.$ $\mathrm{nM})$. However, translating many-fold changes in fluorescence of a high-affinity indicator directly into $\mathrm{Ca}^{2+}$ entry could be complicated by (partial) indicator saturation, potentially resulting in an underestimation of free presynaptic $\mathrm{Ca}^{2+}$ transients.

Our $\mathrm{Ca}^{2+}$-imaging results argue that the electrotonic facilitation of transmission at MF-CA3 pyramidal cell synapses reported previously (Alle and Geiger, 2006) cannot be explained by a change in either resting or action-potential-evoked presynaptic $\mathrm{Ca}^{2+}$ signaling in the bouton. To further address the potential role of highly localized $\mathrm{Ca}^{2+}$ sources (other than $\mathrm{Ca}^{2+}$ channels) in mediating depolarization-dependent synaptic facilitation, we tested whether such facilitation can be suppressed by presynaptic high-affinity $\mathrm{Ca}^{2+}$ buffers or by blockade of $\mathrm{Ca}^{2+}$ stores. Again, the depolarization-induced synaptic enhancement remained intact (Figs. 5-7), also confirming that this phenomenon should not be affected by the use of high-affinity $\mathrm{Ca}^{2+}$ indicators.

One $\mathrm{Ca}^{2+}$-dependent mechanism that cannot be ruled out is that depolarization decreases the effective distance between $\mathrm{Ca}^{2+}$ sources (principally $\mathrm{Ca}^{2+}$ channels) and $\mathrm{Ca}^{2+}$ sensors that trigger exocytosis. Such a decrease could elevate the $\mathrm{Ca}^{2+}$ concentration near the sensor without affecting either presynaptic $\mathrm{Ca}^{2+}$ currents or the bouton-averaged $\mathrm{Ca}^{2+}$-dependent fluorescence. However, this mechanism should be sensitive to $\mathrm{Ca}^{2+}$ buffering: the attenuation of the effect by $10 \mathrm{~mm}$ EGTA (Alle and Geiger, 2006) could be explained by shallower $\mathrm{Ca}^{2+}$ nanodomains that would weaken synaptic facilitation in response to the same change in the $\mathrm{Ca}^{2+}$ sensor-source distance. To test this possibility, we simulated distributed presynaptic $\mathrm{Ca}^{2+}$ entry, diffusion and buffering using the VCell environment (Schaff et al., 1997). Although the model incorporated the experimental estimates of $\mathrm{Ca}^{2+}$ entry (Geiger and Jonas, 2000) and intraterminal buffering (Müller et al., 2005; Scott and Rusakov, 2006) characteristic of giant MF boutons (Fig. 9A-D) (see Materials and Methods), its general features were not important to answer a qualitative question: does adding EGTA make the $\mathrm{Ca}^{2+}$ nanodomains less steep? In fact, simulations showed the opposite: adding EGTA causes the rapid rise in free $\mathrm{Ca}^{2+}$ to attenuate more steeply with distance (Fig. 9D,E). Therefore, the depolarization-dependent decrease in the $\mathrm{Ca}^{2+}$ source-sensor distance, if such exists, should be enhanced in EGTA, opposite to what has been observed (Alle and Geiger, 2006). In addition, $\mathrm{Ca}^{2+}$ sensors that trigger release have been associated with docked and primed, and therefore mostly immobile, synaptic vesicles (Sudhof, 2004), also arguing against the involvement of $\mathrm{Ca}^{2+}$ source-sensor distance changes in the underlying mechanism.

Changes in presynaptic voltage have been reported to modulate $\mathrm{Ca}^{2+}$-triggered exocytosis at the crustacean neuromuscular junction in a $\mathrm{Ca}^{2+}$-independent manner (Hochner et al., 1989). However, this has not been reproduced at mammalian central synapses (Felmy et al., 2003), although voltage-dependent and $\mathrm{Ca}^{2+}$-independent somatic exocytosis has been reported in dorsal root ganglion neurons (Zhang and Zhou, 2002). Overall, the present results suggest that changes in presynaptic membrane 
potential, including those arising from electrotonic propagation of somatic depolarization, affect neurotransmitter release from $\mathrm{MF}$ boutons in a $\mathrm{Ca}^{2+}$-independent manner. By implication, other presynaptic influences on MF bouton membrane potential, such as those mediated by presynaptic kainate and $\mathrm{GABA}_{\mathrm{A}}$ receptors (Kamiya et al., 2002; Ruiz et al., 2003; Alle and Geiger, 2007), may also exert at least part of their action through a mechanism that does not involve changes in $\mathrm{Ca}^{2+}$. Whether this is a general mechanism in the cortex is less clear: electrotonic propagation of depolarization has been shown to affect transmission in cortical pyramidal cells in a $\mathrm{Ca}^{2+}$-dependent manner (Shu et al., 2006). Moreover, somatic depolarization influences presynaptic $\mathrm{Ca}^{2+}$ in proximal MF segments (Ruiz et al., 2003; Scott and Rusakov, 2006). However, a strong $\mathrm{Ca}^{2+}$-indepedent component of evoked glutamate release at central synapses can be revealed by osmotic challenge (Bronk et al., 2007) or by application of nifedipine (Hirasawa and Pittman, 2003). Thus, $\mathrm{Ca}^{2+}$-dependent and $\mathrm{Ca}^{2+}$-independent influences of presynaptic membrane potential on neurotransmitter release are likely to coexist, with different relative contributions at distinct synapses.

\section{References}

Acsády L, Kamondi A, Sik A, Freund T, Buzsáki G (1998) GABAergic cells are the major postsynaptic targets of mossy fibers in the rat hippocampus. J Neurosci 18:3386-3403.

Alle H, Geiger JR (2006) Combined analog and action potential coding in hippocampal mossy fibers. Science 311:1290-1293.

Alle H, Geiger JR (2007) GABAergic spill-over transmission onto hippocampal mossy fiber boutons. J Neurosci 27:942-950.

Bischofberger J, Geiger JR, Jonas P (2002) Timing and efficacy of $\mathrm{Ca}^{2+}$ channel activation in hippocampal mossy fiber boutons. J Neurosci 22:10593-10602.

Blatow M, Caputi A, Burnashev N, Monyer H, Rozov A (2003) $\mathrm{Ca}^{2+}$ buffer saturation underlies paired pulse facilitation in calbindin-D28kcontaining terminals. Neuron 38:79-88.

Bronk P, Deák F, Wilson MC, Liu X, Sudhof TC, Kavalali ET (2007) Differential effects of SNAP-25 deletion on $\mathrm{Ca}^{2+}$-dependent and $\mathrm{Ca}^{2+}$. independent neurotransmission. J Neurophysiol 98:794-806.

Burnashev N, Rozov A (2005) Presynaptic $\mathrm{Ca}^{2+}$ dynamics, $\mathrm{Ca}^{2+}$ buffers and synaptic efficacy. Cell Calcium 37:489-495.

Engel AK, Fries P, Singer W (2001) Dynamic predictions: oscillations and synchrony in top-down processing. Nat Rev Neurosci 2:704-716.

Felmy F, Neher E, Schneggenburger R (2003) The timing of phasic transmitter release is $\mathrm{Ca} 2+$-dependent and lacks a direct influence of presynaptic membrane potential. Proc Natl Acad Sci U S A 100:15200-15205.

Geiger JR, Jonas P (2000) Dynamic control of presynaptic $\mathrm{Ca}^{2+}$ inflow by fast-inactivating $\mathrm{K}^{+}$channels in hippocampal mossy fiber boutons. Neuron 28:927-939.

Gundlfinger A, Bischofberger J, Johenning FW, Torvinen M, Schmitz D, Breustedt J (2007) Adenosine modulates transmission at the hippocampal mossy fibre synapse via direct inhibition of presynaptic calcium channels. J Physiol 582:263-277.

Hirasawa M, Pittman QJ (2003) Nifedipine facilitates neurotransmitter release independently of calcium channels. Proc Natl Acad Sci U S A 100:6139-6144.

Hochner B, Parnas H, Parnas I (1989) Membrane depolarization evokes neurotransmitter release in the absence of calcium entry. Nature 342:433-435
Jackson MB, Redman SJ (2003) Calcium dynamics, buffering, and buffer saturation in the boutons of dentate granule-cell axons in the hilus. J Neurosci 23:1612-1621.

Kamiya H, Ozawa S, Manabe T (2002) Kainate receptor-dependent shortterm plasticity of presynaptic $\mathrm{Ca}^{2+}$ influx at the hippocampal mossy fiber synapses. J Neurosci 22:9237-9243.

Koester HJ, Sakmann B (2000) Calcium dynamics associated with action potentials in single nerve terminals of pyramidal cells in layer $2 / 3$ of the young rat neocortex. J Physiol 529:625-646.

Lauri SE, Bortolotto ZA, Nistico R, Bleakman D, Ornstein PL, Lodge D, Isaac JT, Collingridge GL (2003) A role for $\mathrm{Ca}^{2+}$ stores in kainate receptordependent synaptic facilitation and LTP at mossy fiber synapses in the hippocampus. Neuron 39:327-341.

Li Q, Lau A, Morris TJ, Guo L, Fordyce CB, Stanley EF (2004) A syntaxin 1, Galpha(o), and N-type calcium channel complex at a presynaptic nerve terminal: analysis by quantitative immunocolocalization. J Neurosci 24:4070-4081.

Maravall M, Mainen ZF, Sabatini BL, Svoboda K (2000) Estimating intracellular calcium concentrations and buffering without wavelength ratioing. Biophys J 78:2655-2667.

Mori-Kawakami F, Kobayashi K, Takahashi T (2003) Developmental decrease in synaptic facilitation at the mouse hippocampal mossy fibre synapse. J Physiol 553:37-48.

Müller A, Kukley M, Stausberg P, Beck H, Müller W, Dietrich D (2005) Endogenous $\mathrm{Ca}^{2+}$ buffer concentration and $\mathrm{Ca}^{2+}$ microdomains in hippocampal neurons. J Neurosci 25:558-565.

Oertner TG, Matus A (2005) Calcium regulation of actin dynamics in dendritic spines. Cell Calcium 37:477-482.

Regehr WG, Delaney KR, Tank DW (1994) The role of presynaptic calcium in short-term enhancement at the hippocampal mossy fiber synapse. J Neurosci 14:523-537.

Ruiz A, Fabian-Fine R, Scott R, Walker MC, Rusakov DA, Kullmann DM (2003) GABAA receptors at hippocampal mossy fibers. Neuron 39:961-973.

Rusakov DA, Fine A (2003) Extracellular $\mathrm{Ca}^{2+}$ depletion contributes to fast activity-dependent modulation of synaptic transmission in the brain. Neuron 37:287-297.

Schaff J, Fink CC, Slepchenko B, Carson JH, Loew LM (1997) A general computational framework for modeling cellular structure and function. Biophys J 73:1135-1146.

Schmidt-Hieber C, Jonas P, Bischofberger J (2007) Subthreshold dendritic signal processing and coincidence detection in dentate gyrus granule cells. J Neurosci 27:8430-8441.

Schmitz D, Mellor J, Nicoll RA (2001) Presynaptic kainate receptor mediation of frequency facilitation at hippocampal mossy fiber synapses. Science 291:1972-1976.

Scott R, Rusakov DA (2006) Main determinants of presynaptic $\mathrm{Ca}^{2+} \mathrm{dy}$ namics at individual mossy fiber-CA3 pyramidal cell synapses. J Neurosci 26:7071-7081.

Shu Y, Hasenstaub A, Duque A, Yu Y, McCormick DA (2006) Modulation of intracortical synaptic potentials by presynaptic somatic membrane potential. Nature 441:761-765.

Sudhof TC (2004) The synaptic vesicle cycle. Annu Rev Neurosci 27:509-547.

Tsien RW, Hess P, McCleskey EW, Rosenberg RL (1987) Calcium channels: mechanisms of selectivity, permeation, and block. Annu Rev Biophys Biophys Chem 16:265-290.

Zhang C, Zhou Z (2002) $\mathrm{Ca}^{2+}$-independent but voltage-dependent secretion in mammalian dorsal root ganglion neurons. Nat Neurosci 5:425430 . 